\title{
Professional Learning Communities Assessment - Revised: A Measure of Schools as Learning Organisations
}

\author{
Visal Moosa*, Sallimah Salleh and Lukman Hamid \\ Sultan Hassanal Bolkiah Institute of Education, Universiti Brunei Darussalam, Bandar Seri Begawan, BE1410, \\ Brunei Darussalam
}

\begin{abstract}
Recent years showed a much stronger appeal for transforming schools, among other organisations, into learning organisations. More than two decades into the coining of the term learning organisations, researchers are still in pursuit of proper tools for measuring the construct. The present investigation aims to evaluate the appropriateness of Professional Learning Communities Assessment - Revised (PLCA-R) for assessing schools as learning organisations. Data gathered from 224 elementary teachers were analysed using Confirmatory Factor Analysis (CFA) to validate the dimensionality of the selected tool in an organisational context. The results provided reasonable model fit and validity for the hypothesised six-factor model indicating that PLCA-R is a suitable tool for assessing schools as learning organisations. The findings imply that all the dimensions of PLCs have to be given equal consideration when implementing PLCs in the context of learning organisations.
\end{abstract}

Keywords: Brunei Darussalam, confirmatory factor

ARTICLE INFO

Article history:

Received: 16 July 2019

Accepted: 20 July 2020

Published: 25 December 2020

DOI: https://doi.org/10.47836/pjssh.28.4.31

E-mail addresses:

visal.moosa@gmail.com (Visal Moosa)

sallimah.salleh@ubd.edu.bn (Sallimah Salleh)

lukman.hamid@ubd.edu.bn (Lukman Hamid)

*Corresponding author analysis, learning organisations, professional learning communities, schools

\section{INTRODUCTION}

Gone are the days when schools' role is limited to a 'house of transmitting knowledge' to the minds of future generations. In order to prepare future generations for a rapidly changing world, schools have to develop into a 'laboratory 
of inquiry' for continuous improvement. Hence, the call for transforming schools into learning organisations is becoming stronger (Organisation for Economic Co-operation and Development [OECD], 2016; Senge et al., 2000). A learning organisation is one in which the individuals, teams, and the entire organisation as a whole continuously learn so as to improve their practices (Holyoke et al., 2012). But what exactly does a school look like when it can be regarded as a learning organisation? What are the measures that can be used to assess schools as learning organisations?

Previous studies attempted to validate scales that can assess schools in terms of indicative characteristics of learning organisations (see, for example, Bowen et al., 2007; Higgins et al., 2012). However, these measures are short of certain essential elements that should be in place in a learning organisation. For instance, the leadership aspect of school, which is critical for facilitating learning within the organisation (Hord, 1997) is not significant in the scale compiled and tested by Bowen et al. (2007). Similarly, the aspect of shared vision and goals, which is fundamental to a learning organisation (Senge, 1990), is not incorporated in the scale adapted by Higgins et al. (2012). Thus, a comprehensive measure of school as a learning organisation is required. To this end, the current study aims to test and validate a scale for measuring schools as learning organisations in an Asian context based on Professional Learning Community Assessment - Revised (PLCA-R), a scale developed by previous researchers (Cormier \& Olivier, 2009; Olivier, 2009; Olivier et al., 2010). Such a scale would assist schools, policymakers, and researchers in assessing schools as learning organisations, specifically in the Asian context, which could then promote learning among professionals in schools.

\section{Defining and Measuring Learning Organisations}

After nearly three decades since Senge's (1990) invention of the term learning organisation, the concept is still blurred and needs conceptual clarity (Örtenblad, 2018). One reason for the continued misconception is, perhaps, due to the interchangeable use of a very closely related term - organisational learning, which has a much older history than the former (Turi et al., 2014). Consequently, scholarly debate on clarifying the concept falls into two broad schools; (i) that propagates that learning organisation and organisational learning are distinctive (Argyris, 1999; Tsang, 1997), and (ii) that propagates that they are not entirely independent of each other whereby learning organisation is regarded as a special case of organisational learning (EasterbySmith, 1997) - despite they are concepts on their own right. Nevertheless, we take the stance that organisational learning is a special case (rather a result of) learning organisation (Örtenblad, 2018) as we believe that organisational learning could only take place in an organisation where learning of its members as well teams take place. As a result, we are inclined to using the term learning organisation as opposed 
to organisational learning as the former is more compatible with our understanding of the concept.

According to Örtenblad (2018), there are four broad descriptions of learning organisation identifiable in the existing literature - they are; learning at work, climate for learning, learning structure, and organisational learning. Learning at work is similar to job-embedded learning whereby employees learn in the workplace on aspects that are closely related to their work. Climate for learning is associated with certain conditions that are either necessary or encouraging for learning to occur. These include shared responsibility and accountability, provision of time and resources, an opportunity for experimentation, social as well as relational aspects among employees (Mikkelsen \& Grønhaug, 1999), and emotional aspects such as support, recognition, and jobsatisfaction (Tran, 1998). Learning structure may be translated as the organisation being composed of teams whereby each member of the team learns to perform tasks that are usually done by other members (Örtenblad, 2018). The final description, which is known as organisational learning views the organisation, akin to individuals, as the entity of learning. Of the two opposing opinions on this, as stated before, we regard organisational learning as a sub-version of learning organisation (Örtenblad, 2018).

Interestingly, speaking in the context of education, particularly about schools, all the four descriptions above seem to perfectly match with professional learning processes that take place within schools. First, learning at work is very common, and in fact advocated, in schools, which can be analogous to the in-service training that is conducted in schools. Such training, however, can only be considered jobembedded if the training is authentic (Hunzicker, 2011). Next, the role of leadership, structural, and relational support - which are encompassed within the climate for learning - in collaborative professional learning in schools is highlighted by Hord (2005). Third, the description of the learning structure perfectly aligns with the functions of subject departments in schools. Fourth, once an organisation fits into all of the first three descriptions, it can be claimed that learning is actually taking place in the organisation. Consequently, these organisations would fit into the description of organisational learning, which is regarded as an outcome of learning organisation (Örtenblad, 2018). Hence, we argue that a measure for assessing schools as learning organisations should incorporate all the four descriptions, at least, to a reasonable level. Accordingly, in this study, school as a learning organisation is defined as one in which individuals as well as teams of staff members learn in a climate that is conducive for their learning.

\section{Earlier Research}

With respect to our aim of validating a scale to measure schools as learning organisations, we first provide a review of some of the existing tools that are developed and tested for this (or similar) purposes. 
We begin with the School Success Profile Learning Organisation (SSP-LO) by Bowen et al. (2006). According to the authors, a learning organisation is:

"associated with a core set of conditions and processes that support the ability of an organisation to value, acquire, and use the information and tacit knowledge acquired from employees and stakeholders to successfully plan, implement, and evaluate strategies to achieve performance goals". (pp. 98-99)

The authors argued that these conditions and processes could be used in assessing schools as learning organisations and were composed of (i) specific tasks that were carried out in learning organisations (actions) and (ii) some intangible aspects required to carry out those tasks (sentiments).

As claimed by the authors, the action domain consisted of six dimensions that were identified from previous literature. They were; (1) team orientation, (2) innovation, (3) involvement, (4) information flow, (5) tolerance for error, and (6) results orientation. Likewise, the sentiments domain was also comprised of six dimensions. These were; (1) common purpose, (2) respect, (3) cohesion, (4) trust, (5) mutual support, and (6) optimism. The study found that the two-factor construct was a valid and reliable measure for assessing schools as learning organisations.

The second tool we wish to discuss is the tool adapted by Higgins et al. (2012). Higgins and colleagues' construct was more inclined to the definition of organisational learning whereby it was defined as a higher order of collective learning that extended beyond a single individual; individuals within an organisation thus learnt from one another and/or in groups. Based on the model of Garvin et al. (2008), Higgins et al. (2012) chose an integrated approach of combining cognitive and sociocultural dimensions of organisational learning. They found that a 3-factor model provided a significant model fit to explain organisational learning. The factors were "psychological safety", "experimentation", and "leadership that reinforces learning" - confirming Garvin et al.'s (2008) model.

We examined the above two measures in terms of their representativeness of the broad descriptions of learning organisations explicated before. This was done by investigating the actual items that were included in those tools. Careful interpretation of the items revealed that none of the two measures could adequately address all the four descriptions of learning organisation. In this regard, the proposed tool by Bowen et al. (2007) mainly incorporated the descriptions which are more in line with 'learning at work' and 'climate for learning'. However, there was an insufficient focus on 'learning structure' and 'organisational learning'. Likewise, the tool offered by Higgins et al. (2012) has a limited emphasis on 'learning at work' and 'learning structure' though it has reasonably covered aspects of 'climate for learning' and 'organisational learning'. Hence, the search for a more inclusive assessment of schools as learning organisations is indispensable. 


\section{A Comprehensive Approach}

A quick search of the literature reveals that there already exists a structure for teacher collaborative learning in schools. In view of this, collaborative learning is defined as a philosophy of learning based on the sharing of authorities and acceptance of responsibility which takes into account the abilities and contribution of group members (Panitz, 1999) who maintain a shared understanding of a problem (Roschelle \& Teasley, 1995). Professional Learning Communities (PLCs) is a structure for promoting collaborative teacher learning in schools (and other similar institutions) that has been in place for over two decades. In its broader sense, PLCs is defined as "a group of people sharing and critically interrogating their practice in an on-going, reflective, collaborative, inclusive, learning-oriented, growth-promoting way" (Stoll et al., 2006, p. 223). In the context of schools, PLC is defined as one in which "teachers in a school and its administrators continuously seek and share learning, and act on their learning... [in order to]... enhance their effectiveness as professionals for the students' benefit" (Hord, 1997, p. 1).

Over the years, several tools were employed in assessing PLCs. Of these, School Professional Staff as Learning Community Questionnaire (SPSLCQ) by Hord (1997) is found to be the most comprehensive tool that incorporated a fair share of organisational aspects into assessing schools as PLCs. Not surprisingly, the creator of the tool related her experience of schools that operated as
PLCs to her previous experience of learning organisations (Hord, 1997). Examination of the items as well as the dimensions in this tool shows that it may be more applicable to assess schools as learning organisation as it seems to incorporate all the four descriptions of learning organisations (Örtenblad, 2018) to a reasonable level. Years after the development of SPSLCQ, based on the same dimensions, a new tool known as Professional Learning Community Assessment (PLCA) emerged (Cormier \& Olivier, 2009). In this study, we used the revised version of the tool, PLCARevised (PLCA-R) by Olivier et al. (2010) for investigating its suitability to measure schools as learning organisations.

The PLCA-R is based on the five original dimensions identified by Hord (1997) which make up PLCs. These dimensions, also known as characteristics of PLCs, are; (1) shared values and vision, (2) supportive and shared leadership, (3) collective learning and application of that learning, (4) shared personal practices, and (5) supportive conditions (Hord, 1997, 1998, 2008). The fifth dimension was later broken down into two dimensions; (i) supportive conditions - structure, and (ii) supportive conditions - relationship. The existence of these dimensions is acknowledged by a number of researchers. For instance, the importance of a set of common values and vision was stressed by Stoll et al. (2006) and integration of such values into the culture of learning in schools was stressed by Morrissey (2000). Moreover, an extensively shared leadership (Kastner, 2015) and teacher empowerment 
are necessary (Zhang \& Pang, 2016) for the sustenance of PLCs. Additionally, PLCs should ideally promote collective learning (Hairon \& Dimmock, 2012) and facilitate collaborative practices (Johnson, 2015). Furthermore, the role of PLCs in opening up for sharing and interrogating teaching practices (Hord \& Tobia, 2012) and its impact on changing pedagogy is also significant (Sai \& Siraj, 2015). Finally, it is stressed that PLCs should be associated with a supportive condition in terms of 'structure' and 'relations' (Kilbane, 2009; Olivier \& Hipp, 2010). Hence, we believe that PLCA-R is a comprehensive measure to assess schools as a learning organisation, which embraces all four descriptions of learning organisations.

\section{METHOD}

\section{Measures}

We employed a survey design whereby a pre-validated instrument was employed for data collection. The tool, Professional Learning Community Assessment - Revised (PLCA-R; Olivier, 2009) is composed of six dimensions and has been used in a number of previous studies (see for Burde, 2016; Guerrini, 2013; Liu et al., 2016; Marx, 2015; Stamper, 2015). These dimensions are in line with the five universal dimensions of PLCs identified by Hord (1997). The tool had undergone stringent content validity procedures (Olivier, 2009; Olivier et al., 2010) and the Cronbach alpha reliability of its subscales are reported (Olivier, 2009) as given in Table 1.
Although the original tool has a varying number of items (see Table 1), we selected only five items for each dimension to be included in the survey. This was done by pre-testing the items in terms of (i) its clarity, (ii) relevance to the context and (iii) relevance to the corresponding dimension. During the pre-testing stage, five potential respondents were interviewed by the principal investigator to check their understanding of the statements and obtain their opinion on the coverage of the content. They were also asked to rank the items for each dimension according to the relevance of the items to the associated dimension. The five top-ranked items (as given in Appendix A) were then chosen to be included in the survey.

Despite its extensive use in research, construct validation of PLCA-R is not reported by its creators. However, a recent study in the Turkish context has assessed the validity and reliability of the tool confirming the validity of the constructs as they are given in the original tool (Dogan et al., 2017). According to the authors, the six-factor model provided adequate fit to data $\left(\chi^{2}(965)=2533, \mathrm{p}<.001 ;\right.$ RMSEA $=.048, \mathrm{CFI}=.907 ; \mathrm{TLI}=.900 ; \mathrm{SRMR}$ $=.044 ; \mathrm{AIC}=54293 ; \mathrm{BIC}=55034)$ and also evidence for convergent validity of the constructs (AVE ranged from .49 to .61). However, the discriminant validity analysis in the study was weak to confirm the distinctiveness of the factors. Hence, it necessitated reasons to carry out validation of the construct of PLCs, in general, and as a tool for measuring schools as learning organisations, in particular. 
Table 1

Dimensions of PLCA-R

\begin{tabular}{llll}
\hline \multirow{2}{*}{ Dimensions } & \multicolumn{3}{c}{ Number of items } \\
\cline { 2 - 3 } & $\begin{array}{l}\text { Original } \\
\text { tool }\end{array}$ & $\begin{array}{l}\text { Adapted } \\
\text { tool }\end{array}$ & $\begin{array}{l}\text { Cronbach } \\
\text { alpha }\end{array}$ \\
\hline Shared and Supportive Leadership (SSL) & 11 & 5 & .94 \\
Shared Values and Vision (SVV) & 9 & 5 & .92 \\
Collective Learning and Application (CLA) & 10 & 5 & .91 \\
Shared Personal Practice (SPP) & 7 & 5 & .87 \\
Supportive Conditions - Relationships (SCR) & 5 & 5 & .82 \\
Supportive Conditions - Structures (SCS) & 10 & 5 & .88 \\
\hline
\end{tabular}

\section{Sample Profile and Research Context}

The survey was administered to elementary English language teachers working in public schools of Brunei Darussalam who participated in PLCs. Unfortunately, it was difficult to obtain the exact number of English teachers as teachers at the primary level are not specialised in teaching specific subjects. Despite this difficulty, it was estimated that the total population of primary English teachers would be between 300 to 400 . Due to the limitations in the total population size, the survey was sent to all the public elementary schools based on the principles of total population sampling (Etikan et al., 2016). A total of 241 surveys were received back via the online survey form which was later reduced to 224 after data cleaning. Although fewer than expected, the sample size is deemed adequate based on the minimum recommended sample sizes of 100 to 150 (Anderson \& Gerbing, 1984; Muthén \& Muthén, 2002), and 200 to 400 (Jackson, 2001) for structural equation modelling. Table 2 presents the profile of these participants based on three demographic variables.

As indicated in the table, with reference to all demographic variables (gender, educational qualification, and school cluster), the greatest percentage of teachers were reported to be engaged in PLC activities for a few hours per month. In this regard, $42.4 \%$ of males and $52.4 \%$ of females while $61.5 \%$ of 'no Diploma', $50.0 \%$ of 'Diploma', $48.2 \%$ of 'degree' and $60.0 \%$ of 'Master's degree' teachers were involved in PLCs for a few hours per month. Additionally, with regard to the school clusters, the greatest number of teachers in all the clusters except for cluster 3 was engaged in PLCs to a duration of a few per month. The corresponding percentages for cluster 1, 2, 4 and 5 were $50.5 \%, 64.5 \%$, $57.4 \%$, and $62.5 \%$ respectively. For cluster 3 , the greatest percentage of teachers (38.8\%) was engaged in PLCs for a few hours per week. Given the context of the study, these levels of engagement in PLCs are normal as teachers come together as a 
team usually once a month. The activities of the PLCs revolve around finding the solution to the research problem which the team had identified in the beginning. These activities typically follow an action research approach. In the monthly meetings, teachers discuss the progress they have made so far in their research. The PLC activities for a given year-end with a culmination meeting of all PLCs of the same cluster where they present their final research report.

Table 2

Respondent profile

\begin{tabular}{|c|c|c|c|c|c|c|c|}
\hline \multirow{2}{*}{ Attribute } & & & \multicolumn{4}{|c|}{ Time spent in PLCs } & \multirow{2}{*}{ Total } \\
\hline & & & 1 & 2 & 3 & 4 & \\
\hline \multirow[t]{4}{*}{ Gender } & male & $\mathrm{N}$ & 4 & 14 & 13 & 2 & 33 \\
\hline & & $\%$ & $12.1 \%$ & $42.4 \%$ & $39.4 \%$ & $6.1 \%$ & $100.0 \%$ \\
\hline & female & $\mathrm{N}$ & 32 & 100 & 43 & 16 & 191 \\
\hline & & $\%$ & $16.8 \%$ & $52.4 \%$ & $22.5 \%$ & $8.4 \%$ & $100.0 \%$ \\
\hline \multirow{8}{*}{$\begin{array}{l}\text { Educational } \\
\text { Qualification }\end{array}$} & no & $\mathrm{N}$ & 2 & 8 & 2 & 1 & 13 \\
\hline & diploma & $\%$ & $15.4 \%$ & $61.5 \%$ & $15.4 \%$ & $7.7 \%$ & $100.0 \%$ \\
\hline & diploma & $\mathrm{N}$ & 9 & 36 & 21 & 6 & 72 \\
\hline & & $\%$ & $12.5 \%$ & $50.0 \%$ & $29.2 \%$ & $8.3 \%$ & $100.0 \%$ \\
\hline & degree & $\mathrm{N}$ & 19 & 55 & 31 & 9 & 114 \\
\hline & & $\%$ & $16.7 \%$ & $48.2 \%$ & $27.2 \%$ & $7.9 \%$ & $100.0 \%$ \\
\hline & masters & $\mathrm{N}$ & 6 & 15 & 2 & 2 & 25 \\
\hline & & $\%$ & $24.0 \%$ & $60.0 \%$ & $8.0 \%$ & $8.0 \%$ & $100.0 \%$ \\
\hline \multirow[t]{10}{*}{ School Cluster } & Cluster 1 & $\mathrm{~N}$ & 6 & 16 & 7 & 3 & 32 \\
\hline & & $\%$ & $18.8 \%$ & $50.0 \%$ & $21.9 \%$ & $9.4 \%$ & $100.0 \%$ \\
\hline & Cluster 2 & $\mathrm{~N}$ & 5 & 20 & 4 & 2 & 31 \\
\hline & & $\%$ & $16.1 \%$ & $64.5 \%$ & $12.9 \%$ & $6.5 \%$ & $100.0 \%$ \\
\hline & Cluster 3 & $\mathrm{~N}$ & 11 & 22 & 26 & 8 & 67 \\
\hline & & $\%$ & $16.4 \%$ & $32.8 \%$ & $38.8 \%$ & $11.9 \%$ & $100.0 \%$ \\
\hline & Cluster 4 & $\mathrm{~N}$ & 7 & 31 & 12 & 4 & 54 \\
\hline & & $\%$ & $13.0 \%$ & $57.4 \%$ & $22.2 \%$ & $7.4 \%$ & $100.0 \%$ \\
\hline & Cluster 5 & $\mathrm{~N}$ & 7 & 25 & 7 & 1 & 40 \\
\hline & & $\%$ & $17.5 \%$ & $62.5 \%$ & $17.5 \%$ & $2.5 \%$ & $100.0 \%$ \\
\hline \multirow[t]{2}{*}{ Total } & & $\mathrm{N}$ & 36 & 114 & 56 & 18 & 224 \\
\hline & & $\%$ & $16.1 \%$ & $50.9 \%$ & $25.0 \%$ & $8.0 \%$ & $100.0 \%$ \\
\hline
\end{tabular}

Note: 1 , less than a few hours per month; 2 , a few hours per month; 3 , a few hours per week; 4 , more than a few hours per week 


\section{Data Analysis}

Prior to validation analysis, data were examined in terms of data entry errors, missing values, and suspicious responses using the straight lining method (Hair et al., 2017). While no missing values were identified 17 cases were identified as suspicious and were subsequently deleted from the data set. Moreover, the distributional characteristics of data (for the remaining 224 cases) were assessed using univariate skewness (ranged from -1.41 to -0.35 ) and kurtosis (ranged from -0.54 to +4.80 ) which are within acceptable ranges of -2 to +2 and -7 to +7 for skewness and kurtosis respectively (Curran et al., 1996). Multivariate outliers were examined using AMOS 21 as a measure of assessing the multivariate normality, which revealed the presence of some multivariate outliers. They were, however, used in the analysis as their deletion would be more detrimental to the results. Finally, following stringent recommendations not to do both Exploratory Factor Analysis (EFA) and Confirmatory Factor Analysis (CFA) on the same data (Kline, 2015; Ramayah et al., 2018), only CFA was carried out in this study as the study employed an existing factor structure. Based on the minimum requirements suggested by Kline (2011), five types of indices were involved in evaluating the CFA model; they were (i) chi-square $\left(x^{2}\right)$, (ii) comparative fit index (CFI), (iii) root mean square error of estimate (RMSEA), (iv) standardised root mean square residual (SRMR), and (v) minimum discrepancy divided by degree of freedom (CMIN/DF).
In addition to this, the threshold values for the selected indices employed in this study were $p\left(\chi^{2}\right)>.05$ (Kline, 2015), CFI $\geq .90$ (Byrne, 2016), RMSEA $\leq .1$ (Maccallum et al., 1996), SRMR $\leq .08$ (Byrne, 2016), and CMIN/DF $\leq 5$ (Wheaton et al., 1977).

In order to test the factorial validity of PLCA-R, three a-priori models were hypothesised based on Hord's (1997) dimensions of PLCs. Model A is composed of the original six dimensions as given in the PLCA-R questionnaire while Model B and C were made by merging various constructs. In this regard, Model B merges the dimensions of CLA and SPP as these two dimensions collectively represent the actual engagement of teachers in PLC activities. Similarly, Model $\mathrm{C}$ is formed by the integration of SCS and SCR (in addition to the CLA-SPP integration). The SCS-SCR integration is justified as both the dimensions measure the same construct of supportive conditions within the organisation (Hord, 1997).

\section{FINDINGS}

The a-priori Models A, B, and C were assessed based on the thresholds we embraced in this study for fit indices. The initial models consisted of all five items for all the latent constructs (SSL, SVV, CLA, SPP, SCS, and SCR). None of the initial models depicted adequate fit to data based on the employed fit indices. The models were then modified by deleting potentially weak items and drawing covariances. These modifications, however, were stringent so that the assumptions of a confirmatory analysis were not violated. In this regard, the 
deletion of items was kept to a minimum, not exceeding the recommended $20 \%$ limit (Ramayah et al., 2018). Furthermore, covariances were only drawn between items belonging to the same latent construct - they were not drawn across different constructs despite such modifications were suggested by AMOS. Figure 1, 2, and 3 represent the final models after minimum possible modifications to Models A, B, and C respectively.

The associated fit indices for the final Models A, B, and C are shown in Table 3.
According to the results in Table 3, Model $\mathrm{A}\left(x^{2}(232)=563 ; \mathrm{RMSEA}=.080 ; \mathrm{CFI}\right.$ $=.917$; SRMR $=.049)$ as well as Model B $\left(x^{2}(237)=575\right.$; $\mathrm{RMSEA}=.080 ; \mathrm{CFI}=.918$; SRMR $=.048)$ depicts a reasonable fit to data (Byrne, 2016; Maccallum et al., 1996; Wheaton et al., 1977). Model C, however, portrays a mediocre fit to data $\left(x^{2}(240)=\right.$ 631; RMSEA =.085; CFI =.910; SRMR $=.047$ ). As none of the models can be discarded for having a poor fit to data, they were all considered for further evaluation by convergent and discriminant validity.

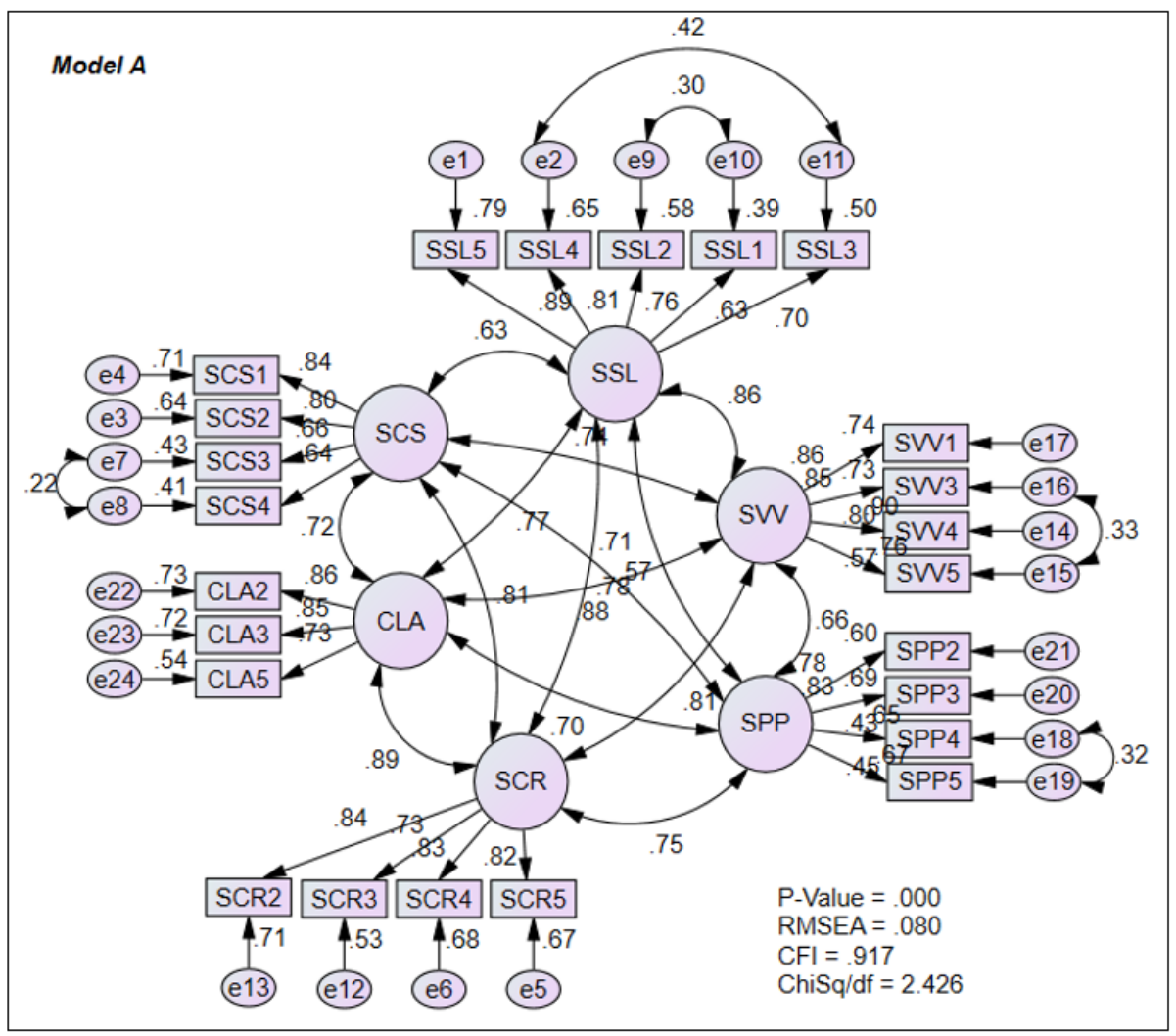

Figure 1. Hypothesised Model A (6 factor model) 


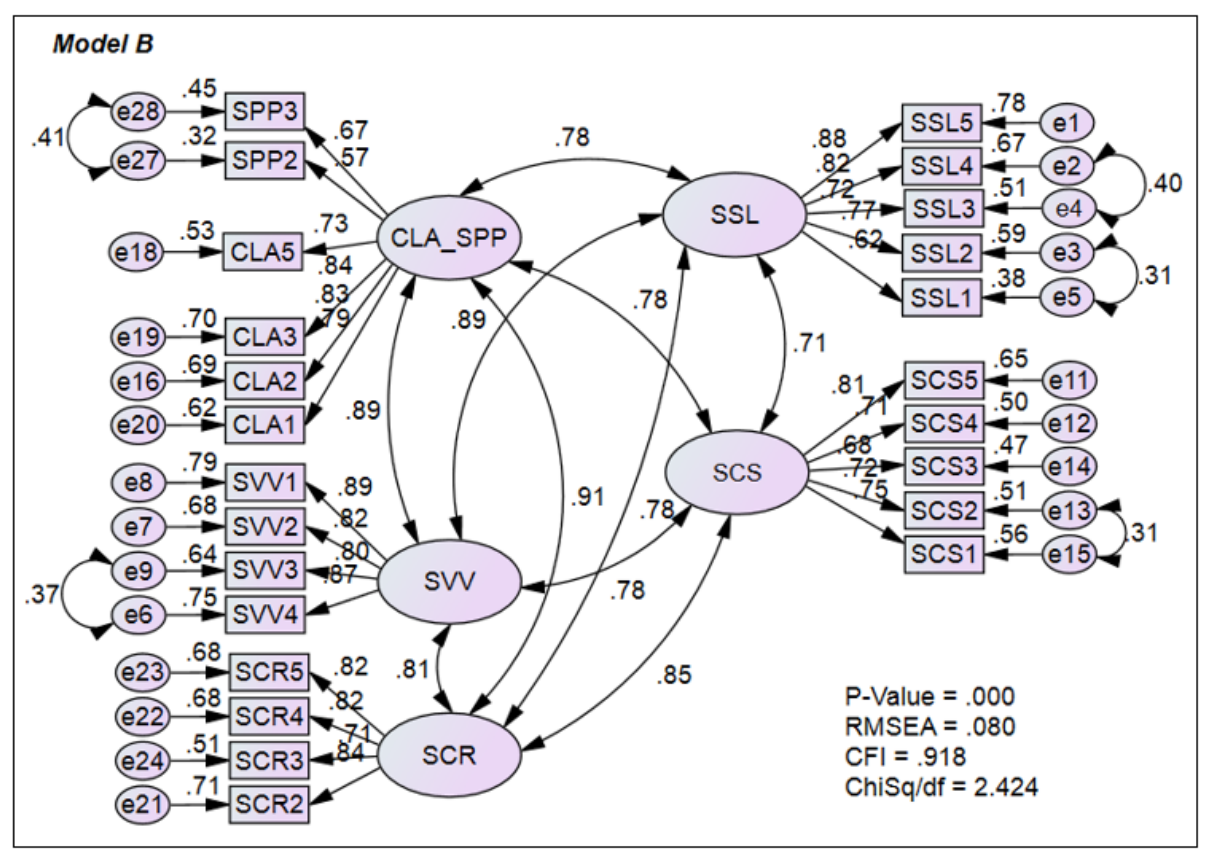

Figure 2. Hypothesised Model B (5 factor model)

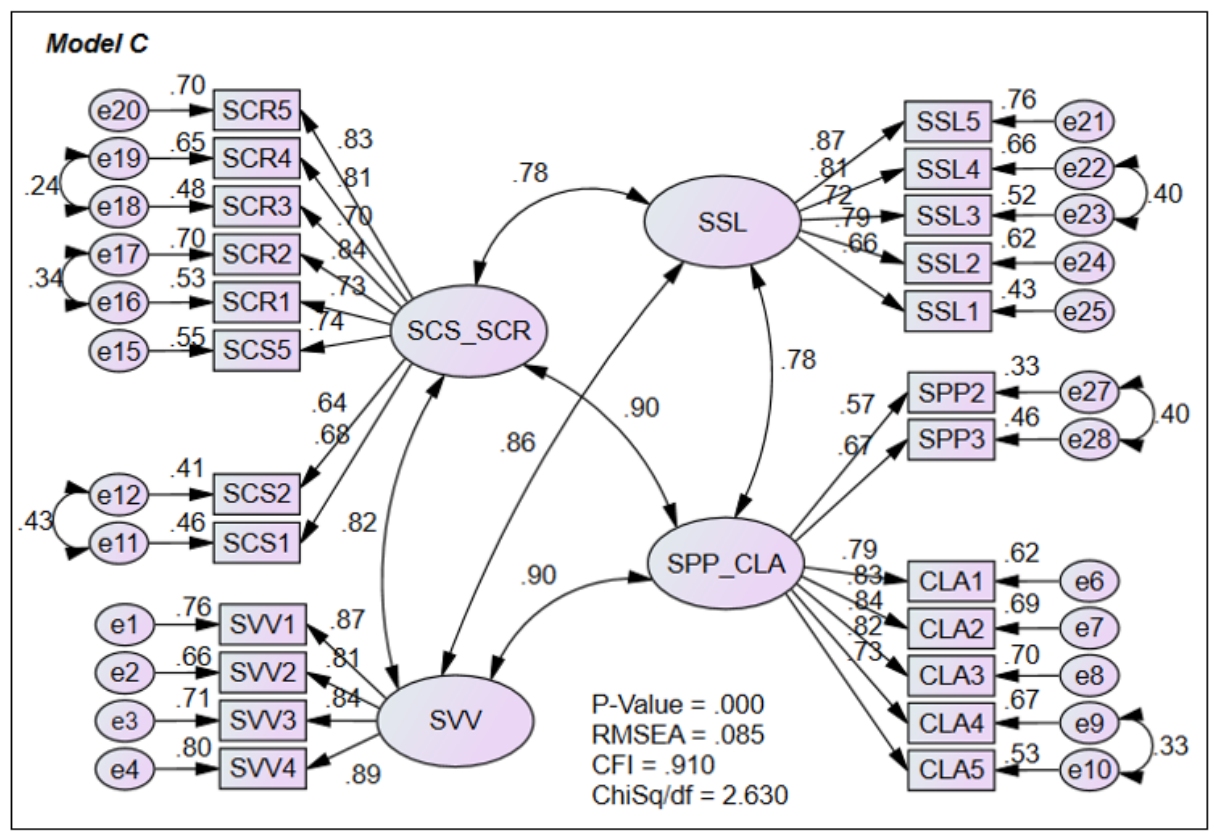

Figure 3. Hypothesised Model C (4 factor model) 
Table 3

Fit indices for the final models

\begin{tabular}{lllllll}
\hline Model & $x^{2}$ & $\mathrm{df}$ & CMIN/DF & RMSEA & CFI & SRMR \\
\hline Model A & 562.921 & 232 & 2.426 & .080 & .917 & .049 \\
Model B & 574.510 & 237 & 2.424 & .080 & .918 & .048 \\
Model C & 631.197 & 240 & 2.630 & .085 & .910 & .047 \\
\hline
\end{tabular}

In the present study, convergent validity was examined using Composite Reliability (CR) and Average Variance Extracted (AVE) while discriminant validity was assessed using correlation among the latent factors. The thresholds for acceptance of convergent validity are $C R \geq .70$ (Raykov, 2004) and AVE $\geq .50$ (Kline, 2015). For discriminant validity, the inter-factor correlation $\leq .90$ was considered as the cut-off (Byrne, 2001). Table 4, 5, and 6 display the obtained values for $\mathrm{CR}, \mathrm{AVE}$, and correlations for the three models evaluated in this study.

According to the results in Table 4, model A passes the assessment of both the convergent and discriminant validity based on the above criteria. Particularly, the CR was between .824 and .907 while the AVE ranged from .541 to .709 for all the dimensions. Furthermore, none of the correlations between the dimensions is above 90 .

Table 4

Construct validity for Model A

\begin{tabular}{lccccccc}
\hline Factors & CR & AVE & SSL & SCR & SVV & SPP & CLA \\
\hline SSL & .874 & .584 & & & & & \\
SCR & .880 & .647 & .778 & & & & \\
SVV & .907 & .709 & .864 & .812 & & & \\
SPP & .824 & .541 & .567 & .751 & .662 & & \\
CLA & .855 & .664 & .767 & .886 & .876 & .698 & \\
SCS & .826 & .547 & .629 & .812 & .741 & .706 & .721 \\
\hline
\end{tabular}

In contrast, as indicated by the results validity. The CR for each factor was above in Table 5, model B passed the assessment .70 while AVE was above .50 . However, the of convergent validity but not discriminant correlation between two of the dimensions 
of CLA/SPP and SCR was above .90 indicating that they measured constructs that were too similar. Hence, construct validity for model B could not be confirmed.

Similarly, results in Table 6 revealed that model C, as well, could not pass the test of discriminant validity despite achieving acceptable convergent validity. The $\mathrm{CR}$ for all the factors were above. 70 and AVEs are above .50. However, the correlation between two pairs of dimensions (SCS/SCR with CLA/SPP and SVV with CLA/SPP) are above .90 indicating that these measures were not truly distinct from one another. Hence, construct validity for model $\mathrm{C}$ could not be achieved.
The results indicate that Model A which was composed of the original six dimensions of PLCA-R is the best model to assess PLCs in an organisational context. Although both Model A and B showed a reasonable fit to data, only Model A could pass the discriminant validity assessment. Hence, the findings show that PLCs in schools is a multidimensional construct. Specifically, the findings provide supporting evidence for the existing six-factor structure of PLCA-R. Subsequently, based on the theoretical justifications present before, PLCA-R can be employed to assess schools as learning organisations.

Table 5

Construct validity for Model B

\begin{tabular}{lcccccc}
\hline Factors & CR & AVE & SSL & SVV & SCS & SCR \\
\hline SSL & .875 & .586 & & & & \\
SVV & .910 & .716 & .886 & & & \\
SCS & .853 & .538 & .715 & .780 & & \\
SCR & .879 & .645 & .776 & .809 & .850 & \\
CLA/SPP & .879 & .552 & .778 & .890 & .783 & .914 \\
\hline
\end{tabular}

Table 6

Construct validity for Model C

\begin{tabular}{lcclll}
\hline Factors & CR & AVE & CLA/SPP & SCS/SCR & SSL \\
\hline CLA/SPP & .902 & .571 & & & \\
SCS/SCR & .910 & .561 & .904 & & \\
SSL & .881 & .599 & .776 & .781 & \\
SVV & .916 & .733 & .903 & .822 & .857 \\
\hline
\end{tabular}




\section{DISCUSSION AND CONCLUSIONS}

This study intended to construct validate the tool PLCA-R for measuring schools as learning organisations. We found that the six-factor as well as the five-factor models provided a reasonable fit to data. However, only the six-factor model could provide discriminant validity for the dimensions. Previous studies that carried out the validation of PLCA-R in other contexts reported empirical support for the six-factor model (Dogan et al., 2017). At the same time, PLCA-R incorporates a wider span of concepts that reasonably match with all four descriptions of learning organisations reported in the literature (Örtenblad, 2018). Furthermore, the close association between operations of learning organisation and PLCs reported by Hord (1997) provides theoretical support for our argument that schools operating as professional learning communities are analogous to learning organisations. Hence, we claim that the validated version of PLCA-R (Olivier et al., 2010) as reported in the current study is appropriate to assess schools as learning organisations.

The six factors in the validated model correspond to six dimensions of PLCs. These are shared and supportive leadership (SSL), shared values and vision (SVV), collective learning and application (CLA), shared personal practice (SPP), supportive conditions - relationships (SCR), and supportive conditions - structures (SCS). The findings suggest that each of these dimensions is an essential constituent of schools that may resemble learning organisations.

First, leadership in schools must be distributed widely in such a way that duties and responsibilities are shared among teachers. When leadership is shared, teachers feel empowered and encouraged to take initiatives in advancing teaching and learning (Zhang \& Pang, 2016) eventually promoting the school as a learning organisation. In addition to having a distributed-leadership that supports the day-to-day learning engagement in schools, these activities need to be guided by a set of shared norms, values, and vision (Morrissey, 2000) whereby such norms place high importance on the increased student as well as teacher learning (Hord, 1997; Stoll et al., 2006).

The next two dimensions, 'collective learning and application' and 'shared personal practice', represent the real actions of teachers learning as an organisation. The notion of collective learning ceases the legacy of a one-room school house (Glickman et al., 2010) promoting collaborative learning of teachers at grade and school level (Hord, 2008). The essence of this dimension is not only learning together but also applying that learning (Morrissey, 2000) so as to continue the cycle of learning and application of that learning. In doing so, teachers share their instructional practices by means of peer observation and critical review of one another's practice 
(Hord \& Tobia, 2012) which is pivotal to teacher learning and improving classroom teaching (Sai \& Siraj, 2015).

The final set of dimensions refers to the structural and relational conditions in schools that must be in place in order to sustain a learning organisation. Structural conditions include such aspects as time, resources, facilities, policies, and procedures, all of which must be aligned to facilitate collaborative learning of professionals in schools (Hord, 2008; Kilbane, 2009; Stoll et al., 2006). Specifically, there must be time designated and protected for learning, the procedures must allow teachers to observe and provid feedback on one another's teaching, and school facilities must be conducive for teachers to come together and learn in groups. Finally, relational aspects such as trust, openness, and interdependence among staff are cultural elements that is essential to foster learning of professionals in schools (Gray et al., 2016).

Having stressed the importance of the six dimensions of the validated model, we acknowledge the slightly less incorporation of the description of 'learning structure' (one of the four descriptions of learning organisations explicated before) in the model. Examinations of the questionnaire items reveal that those that specifically measure the extent to which a learning structure exists are limited. Hence, we suggest that the measurement of schools' readiness to cover-up the duties of team members when they are not able to perform theirs (Örtenblad, 2018) needs to be better integrated into the model. Such a structure of implementing PLCs has already been proposed by Sather (2009). The author proposed a practical guide for implementing PLCs via Professional Learning Team (PLTs) which were equivalent to subject departments in schools. The integration of this aspect into PLCA-R could prove a better representation of the said description (learning structure) of learning organisations in the model.

\section{Implications}

The findings of the present study provide implications for research, literature, and practice. First, the analyses provided adequate convergent and discriminant validity for the constructs. Hence, it implies that PLCA-R with the six dimensions of SSL, SVV, CLA, SPP, SCR, and SCCs could be used to assess schools as learning organisations. Researchers may wish to use the shorter version of PLCA-R that is reported in this paper, properly acknowledging the original source of the tool.

Second, given the limitation of PLCA-R in addressing the aspect of learning structures in PLC-schools, researchers may endeavour to develop items in order to capture the specific concept. The new items should assess schools' capability to perform the duties of staff who may be unable to perform theirs for some reason. These new items may be incorporated into relevant dimensions in the existing model 
or may appear as a separate dimension in a new model depending on the results of appropriate statistical analysis.

Third, schools wishing to function as learning organisations should strive to perform well in all the six dimensions that were incorporated in the validated model as these were found to be significantly different aspects of schools as learning organisations. Hence, in addition to the professional learning aspects (represented by CLA and SPP) attention must also be paid to those dimensions that are specific to organisational context, namely 'shared and supportive leadership' and 'supportive conditions - structure'. Likewise, equal importance must also be given to 'shared values and vision' and supportive conditions - relationship'.

\section{Limitations}

The present study is constrained by certain limitations. Firstly, the small sample size due to the stringent choice of teachers teaching a specific subject limits the generalisability of the findings. As such, large-scale studies with bigger sample sizes and a wide range of subject teachers are necessary to confirm the findings of this study. Secondly, the interpretations of the results from the present study might have suffered from, to some extent, violation of the assumption of multivariate normality as few multivariate outliers were included in the analyses. Although this may not have significantly affected the present findings, as it was based on total population sampling, researchers who might employ the model in the future are advised to be cautious. Finally, this study did not investigate the amount of teacher-learning that resulted in teachers' engagement in PLCs. It only measured what teachers did and what they saw as characteristics of their respective schools as PLCs. Consequently, we could not comment on whether a school that may be labelled as a learning organisation (based on the six dimensions) does really promote the learning of its teachers. Hence, it is recommended that future research should extend the model to include a construct in the questionnaire to measure the amount of learning that takes place in the organisation.

\section{ACKNOWLEDGEMENT}

The researchers would like to thank all teachers and their respective schools for taking part in the survey from which data was gathered for the analysis.

\section{REFERENCES}

Anderson, J. C., \& Gerbing, D. W. (1984). The effect of sampling error on convergence, improper solutions, and goodness-of-fit indices for maximum likelihood confirmatory factor analysis. Psychometrika, 49(2), 155-173. doi: 10.1007/BF02294170

Argyris, C. (1999). On organizational learning. Oxford, USA: Blackwell.

Bowen, G. L., Rose, R. A., \& Ware, W. B. (2006). The reliability and validity of the school success profile learning organization measure. Evaluation and Program Planning, 29, 97-104. doi: 10.1016/j.evalprogplan.2005.08.005

Bowen, G. L., Ware, W. B., Rose, R. A., \& Powers, J. D. (2007). Assessing the functioning of schools 
as learning organizations. Children \& Schools, 29(4), 199-208. doi:10.1093/cs/29.4.199

Burde, M. S. (2016). The relationship between student achievement and professional learning communities at the middle school level (Doctoral dissertation). Available from ProQuest Dissertations \& Theses Global. (UMI No. 10297206).

Byrne, B. M. (2001). Structural equation modeling with AMOS: Basic concepts, applications, and programming. Mahwah, USA: Lawrence Erlbaum Associates.

Byrne, B. M. (2016). Structural equation modeling with Amos: Basic concepts, applications, and programming (3rd ed.). New York, USA: Routledge.

Cormier, R., \& Olivier, D. F. (2009). Professional learning communities: Characteristics, principals, and teachers. Annual Meeting of the Louisiana Education Research Association [Conference presentation]. Louisiana, USA. Retrieved August 11, 2019, from https:// www.researchgate.net/profile/Dianne_Olivier/ publication/228537695_Professional_Learning_ Committees_Characteristics_Principals_and_ Teachers/links/556c754508aec2268305404f.pdf

Curran, P. J., West, S. G., \& Finch, J. F. (1996). The robustness of test statistics to nonnormality and specification error in confirmatory factor analysis. Psychological Methods, 1(1), 16-29. doi: 10.1037/1082-989X.1.1.16

Dogan, S., Tatık, R. S., \& Yurtseven, N. (2017). Professional learning communities assessment: Adaptation, internal validity, and multidimensional model testing in Turkish context. Educational Sciences: Theory \& Practice, 17, 1203-1229. doi: 10.12738/ estp.2017.4.0479
Easterby-Smith, M. (1997). Disciplines of organizational learning: Contributions and critiques. Sociological Methods \& Research, 50(9), 1085-1113. doi: 10.1177/016344300022005001

Etikan, I., Musa, S. A., \& Alkassim, R. S. (2016). Comparison of convenience sampling and purposive sampling. American Journal of Theoretical and Applied Statistics, 5(1), 1-4. doi: 10.11648/j.ajtas.20160501.1

Garvin, D. A., Edmondson, A. C., \& Gino, F. (2008). Is yours a learning organization? Harvard Business Review, 86(3), 109-116.

Glickman, C. D., Gordon, S. P., \& Ross-Gordon, J. M. (2010). Supervision and instructional leadership: A developmental approach. Boston, USA: Pearson/Allyn and Bacon.

Gray, J., Kruse, S., \& Tarter, C. J. (2016). Enabling school structures, collegial trust and academic emphasis: Antecedents of professional learning communities. Educational Management Administration and Leadership, 44(6), 875-891. doi: 10.1177/1741143215574505

Guerrini, J. (2013). A quantitative study of the relationship among the constructs of trust, professional learning communities, and capacity building within the high school setting (Doctoral dissertation). Available from ProQuest Dissertations \& Theses Global. (UMI No. 3589985).

Hair, J. F., Hult, G. T., Ringle, C. M., \& Sarstedt, M. (2017). A primer on partial least squares structural equation modeling ( 2 nd ed.). Thousand Oaks, USA: Sage Publications Inc.

Hairon, S., \& Dimmock, C. (2012). Singapore schools and professional learning communities: Teacher professional development and school leadership in an Asian hierarchical system. Educational Review, 64(4), 405-424. doi: 10.1080/00131911.2011.625111 
Higgins, M., Ishimaru, A., Holcombe, R., \& Fowler, A. (2012). Examining organizational learning in schools: The role of psychological safety, experimentation, and leadership. Journal of Educational Change, 13(1), 67-94. doi: 10.1007/ s10833-011-9167-9

Holyoke, L. B., Sturko, P. A., Wood, N. B., \& Wu, L. J. (2012). Are academic departments perceived as learning organizations? Educational Management Administration \& Leadership, 40(4), 436-448. doi: 10.1177/1741143212438219

Hord, S. (1997). Professional learning communities: Communities of continuous inquiry and improvement. Texas, USA: Southwest Educational Development Laboratory.

Hord, S. (1998). Creating a professional learning community: Cottonwood creek school. Issues About Change, 6(2), 2-8.

Hord, S. (2005). Learning together, leading together: Changing schools through professional learning communities. New York, USA: Teachers College Press.

Hord, S. (2008). Evolution of the professional learning community. Journal of Staff Development, 29(3), 10-13.

Hord, S., \& Tobia, E. (2012). Reclaiming our teaching professions: The power of educators learning in community. New York, USA: Teachers College Press.

Hunzicker, J. (2011). Effective professional development for teachers: A checklist. Professional Development in Education, 37(2), 177-179. doi: 10.1080/19415257.2010.523955

Jackson, D. L. (2001). Sample size and number of parameter estimates in maximum likelihood confirmatory factor analysis: A Monte Carlo investigation. Structural Equation Modeling, 8(2), 205-223. doi: 10.1207/S15328007SEM0802 3

Johnson, K. N. (2015). The influence of professional learning communities on instructional, reflective, and collaborative practices (Doctoral dissertation). Available from ProQuest Dissertations \& Theses Global. (UMI No. 3707342).

Kastner, P. M. (2015). Educator perceptions of the impact of professional learning communities on professional growth and student learning. (Doctoral dissertation). Available from ProQuest Dissertations \& Theses Global. (UMI No. 3739266).

Kilbane, J. F. (2009). Factors in sustaining professional learning community. NASSP Bulletin, 93(3), 184205. doi: 10.1177/0192636509358923

Kline, R. B. (2011). Principles and practice of structural equation modeling. New York, USA: Guilford Press.

Kline, R. B. (2015). Principles and practice of structural equation modeling (2nd ed.). New York, USA: Guilford Press.

Liu, S., Hallinger, P., \& Feng, D. (2016). Supporting the professional learning of teachers in China: Does principal leadership make a difference? Teaching and Teacher Education, 59, 79-91. doi: $10.1016 /$ j.tate 2016.05 .023

Maccallum, R. C., Browne, M. W., \& Sugawara, H. M. (1996). Power analysis and determination of sample size for covariance structure modeling of fit involving a particular measure of model. Psychological Methods, 1(2), 130-149. doi: 10.1037/1082-989X.1.2.130

Marx, M. D. (2015). An analysis of variance in teacher self-efficacy levels dependent on participation time in professional learning communities (Doctoral dissertation). Available from ProQuest Dissertations \& Theses Global. (UMI No. 10109490).

Mikkelsen, A., \& Grønhaug, K. (1999). Measuring organizational learning climate: A cross-national replication and instrument validation study 
among public sector employees. Review of Public Personnel Administration, 19(4), 31-44. doi: 10.1177/0734371X9901900404

Morrissey, M. S. (2000). Professional learning communities: An ongoing exploration. Austin, USA: Southwest Educational Development Laboratory.

Muthén, L. K., \& Muthén, B. O. (2002). How to use a Monte Carlo study to decide on sample size and determine power. Structural Equation Modeling: A Multidisciplinary Journal, 9(4), 599-620. doi: 10.1207/S15328007SEM0904 8

Organisation for Economic Co-operation and Development. (2016). What makes a school a learning organisation? A guide for policy makers, school leaders and teachers. Paris, France: OECD.

Olivier, D. F. (2009). Professional learning communities assessment - Revised. Annual Meeting of the Louisiana Education Research Association, Louisiana, USA. Retrieved June 6, 2019, from http://ullresearch.pbworks.com/f/ Olivier_Assessing_PLCs_Symposium_-PLCA-R_Introduction.pdf.

Olivier, D. F., Hipp, K. K., \& Huffman, J. B. (2010). Assessing and analyzing schools as professional learning communities. In K. K. Hipp \& J. B. Huffman (Eds.), Demystifying professional learning communities: School leadership at its best (pp. 29-41). Lanham, USA: R\&L Education.

Örtenblad, A. (2018). What does "learning organization" mean? The Learning Organization, 25(3), 150-158. doi: 10.1108/TLO-02-20180016

Panitz, T. (1999). Collaborative versus cooperative learning: A comparison of the two concepts which will help us understand the underlying nature of interactive learning. Retrieved August 11, 2019, from https://files.eric.ed.gov/fulltext/ ED448443.pdf
Ramayah, T., Cheah, J., Chuah, F., Ting, H., \& Memon, M. A. (2018). Partial least square structural equation modeling (PLS-SEM) using SmartPLS 3.0: An updated and practical guide to statistical analysis. Kuala Lumpur, Malaysia: Pearson Malaysia.

Raykov, T. (2004). Behavioral scale reliability and measurement invariance evaluation using latent variable modeling. Behavior Therapy, 35, 299331.

Roschelle, J., \& Teasley, S. D. (1995). The construction of shared knowledge in collaborative problem solving. In C. E. O’Malley (Ed.), ComputerSupported Collaborative Learning (pp. 69-197). Berlin, Germany: Springer-Verlag.

Sai, X., \& Siraj, S. (2015). Professional learning community in education: Literature review. The Online Journal of Quality in Higher Education, 2(2), 65-78.

Sather, S. E. (2009). Leading professional learning teams. Thousand Oaks, USA: Corwin.

Senge, P., Cambron-McCabe, N., Lucas, T., Smith, B., Dutton, J., \& Kleiner, A. (2000). Schools that learn: A fifth discipline fieldbook for educators, parents, and everyone who cares about education. New York, USA: Doubleday.

Senge, P. M. (1990). The fifth discipline: The art and practice of the learning organization. New York, USA: Doubleday.

Stamper, J. C. (2015). A study of teacher and principal perceptions of professional learning communities (Doctoral dissertation). Available from Theses and Dissertations - Educational Leadership Studies. (Paper No. 11).

Stoll, L., Bolam, R., McMahon, A., Wallace, M., \& Thomas, S. (2006). Professional learning communities: A review of the literature. Journal of Educational Change, 7(4), 221-258. doi: 10.1007/s10833-006-0001-8 
Tran, V. (1998). The role of the emotional climate in learning organisations. The Learning Organization, 5(2), 99-103. doi: $10.1108 / 09696479810212060$

Tsang, E. W. K. (1997). Organizational learning and the learning organization: A dichotomy between. Human Relations, 50(1), 73-89. doi: $10.1177 / 001872679705000104$

Turi, A., Sorooshian, S., Mahmud, F., \& Javed, Y. (2014). The cognitive, behavioral and social prospectives of organizational learning through information system. Malaysian Online Journal of Educational Management, 2(1), 48-61. doi:10.22452/mojem.vol6no3.4
Wheaton, B., Muthén, B., Alwin, D. F., \& Summers, G. F. (1977). Assessing reliability and stability in panel models. Sociological Methodology, 8, 84-136. doi: $10.2307 / 270754$

Zhang, J., \& Pang, N. S.-K. (2016). Exploring the characteristics of professional learning communities in China: A mixed-method study. Asia-Pacific Education Researcher, 25(1), 11-21. doi: 10.1007/s40299-015-0228-3 


\section{APPENDIX A}

\begin{tabular}{|c|c|}
\hline Code & Statements \\
\hline SSL1 & $\begin{array}{l}\text { Staff members are consistently involved in discussing and making decisions about } \\
\text { most school issues. }\end{array}$ \\
\hline SSL2 & The principal incorporates advice from staff members to make decisions. \\
\hline SSL3 & The principal is proactive and addresses areas where support is needed. \\
\hline SSL4 & The principal shares responsibility and rewards for innovative actions. \\
\hline SSL5 & Leadership is promoted and nurtured among staff members. \\
\hline SVV1 & $\begin{array}{l}\text { A collaborative process exists for developing a shared sense of values among } \\
\text { staff. }\end{array}$ \\
\hline SVV2 & $\begin{array}{l}\text { Shared values support norms of behaviour that guide decisions about teaching and } \\
\text { learning. }\end{array}$ \\
\hline SVV3 & $\begin{array}{l}\text { Staff members share visions for school improvement that have an undeviating } \\
\text { focus on student learning. }\end{array}$ \\
\hline SVV4 & A collaborative process exists for developing a shared vision among staff. \\
\hline SVV5 & Policies and programs are aligned to the school's vision. \\
\hline CLA1 & $\begin{array}{l}\text { Collegial relationships exist among staff members that reflect a commitment to } \\
\text { school improvement efforts. }\end{array}$ \\
\hline CLA2 & $\begin{array}{l}\text { Staff members work together to search for solutions to address diverse student } \\
\text { needs. }\end{array}$ \\
\hline CLA3 & $\begin{array}{l}\text { Staff members engage in dialogue that reflects a respect for diverse ideas that lead } \\
\text { to continued inquiry. }\end{array}$ \\
\hline CLA4 & School staff members learn together and apply new knowledge to solve problems. \\
\hline CLA5 & $\begin{array}{l}\text { Staff members collaboratively analyse student work to improve teaching and } \\
\text { learning. }\end{array}$ \\
\hline SPP1 & Opportunities exist for staff members to observe peers. \\
\hline SPP2 & Staff members provide feedback to peers related to instructional practices. \\
\hline SPP3 & $\begin{array}{l}\text { Staff members informally share ideas and suggestions for improving student } \\
\text { learning. }\end{array}$ \\
\hline SPP4 & Opportunities exist for coaching and mentoring. \\
\hline SPP5 & $\begin{array}{l}\text { Individuals and teams have the opportunity to share the results of their } \\
\text { professional practices. }\end{array}$ \\
\hline SCR1 & Caring relationships exist among staff that are built on trust and respect. \\
\hline SCR2 & A culture of trust and respect exists for taking risks. \\
\hline SCR3 & $\begin{array}{l}\text { Outstanding staff achievement is recognised and celebrated regularly in our } \\
\text { school. }\end{array}$ \\
\hline
\end{tabular}




\section{APPENDIX A}

\begin{tabular}{|c|c|}
\hline Code & Statements \\
\hline SCR4 & $\begin{array}{l}\text { School staff and stakeholders exhibit a sustained and unified effort to embed } \\
\text { change into the culture of the school. }\end{array}$ \\
\hline SCR5 & $\begin{array}{l}\text { Relationships among staff members support a discussion of confidential data to } \\
\text { enhance teaching and learning. }\end{array}$ \\
\hline SCS1 & Time is provided to facilitate collaborative work. \\
\hline SCS2 & The school schedule promotes collective learning. \\
\hline SCS3 & Appropriate instructional materials are available to staff. \\
\hline SCS4 & Resource people provide expertise and support for continuous learning. \\
\hline SCS5 & Communication systems promote a flow of information among staff members. \\
\hline
\end{tabular}

